\title{
ЛАЗЕРНЫЕ ТЕХНОЛОГИИ ПРИ ЭНДОДОНТИЧЕСКОМ ЛЕЧЕНИИ ГНОЙНОГО ПУЛЬПИТА И НЕКРОЗА ПУЛЬПЫ
}

\section{LASER TECHNOLOGIES FOR ENDODONTIC TREATMENT OF PURULENT PULPITIS AND PULP NECROSIS}

\author{
A. Polevaya \\ E. Borisova \\ L. Polevaya
}

Summary. 106 patients with confirmed diagnoses of purulent pulpitis (K04.02) and pulp necrosis (K04.1) were selected for the study. Patients were divided into 3 clinical groups depending on the treatment Protocol. It was found that the use of Er, Cr: YSGG laser with a wavelength of 2780 $\mathrm{nm}$ is effective in the treatment of various forms of pulpitis complicated by the presence of Candida fungi.

Keywords: pulpitis, pulp necrosis, Candida fungi, Er, Cr: YSGG laser.

\author{
Полевая Александра Викторовна \\ Преподаватель, Военно-медицинская академия \\ имени С. М. Кирова, Санкт-Петербург \\ dr.polevayaalexandra@rambler.ru \\ Борисова Элеонора Геннадиевна \\ Д.м.н., профессор, Военно-медицинская академия \\ имени С. М. Кирова, Санкт-Петербург \\ Полевая Лариса Петровна \\ Дочент, Военно-медицинская академия имени \\ С.М. Кирова, Санкт-Петербург
}

Аннотация. Для исследования было отобрано 106 пациентов с подтверждёнными диагнозами гнойный пульпит (К04.02) и некр0з пульпы (К04.1). Пациенты были разделены на 3 клинические группы в зависимости от протокола лечения. Установлено, что применение $\mathrm{Er}, \mathrm{Cr}$ : YSGG лазера с длиной волны 2780 нм является эффективным при лечении различных форм пульпита, осложнённых наличием грибов рода Candida.

Ключевые слова: пульпит, некр0з пульпы, грибы рода Candida, Er, Cr: YSGG лазер.

области и их осложнения, угрожающие здоровью и жизни пациента. Чаще всего из гнойного очага высевается микрофлора кариозной полости и корневых каналов причинного зуба.

В течение последних десятилетий Enterococcus faecalis и Candida albicans были широко ассоциированными микроорганизмами при лечении осложненных форм кариеса. Дрожжеподобные микроорганизмы обнаруживаются в запломбированных каналах зубов с неблагоприятным исходом лечения. Фактически показано, что Candida albicans устойчива к медикаментам, обычно применяемым в эндодонтии. После эндодонтического лечения Enterococcus faecalis и Candida albicans способны поддерживать воспалительные процессы в периодонте и определять неудачный исход лечения осложнённых форм кариеса [2, 3]

Несмотря на внедрение в практику врачей-стоматологов новейших достижений науки и техники, проблема эндодонтического лечения остаётся актуальной. Исследования М. K. Caliscan, B.H Sen, 1996, показали, что бактерии способны проникать в дентинные канальцы на глубину 1000 мкм, а раствор гипохлорита натрия проникает на глубину до 100 мкм, что не позволяет добиться полной дезинфекции системы корневого канала. Moritz et al., 2006, в своих исследованиях in vitro продемон- 
Таблица 1. Распределение пациентов на группы.

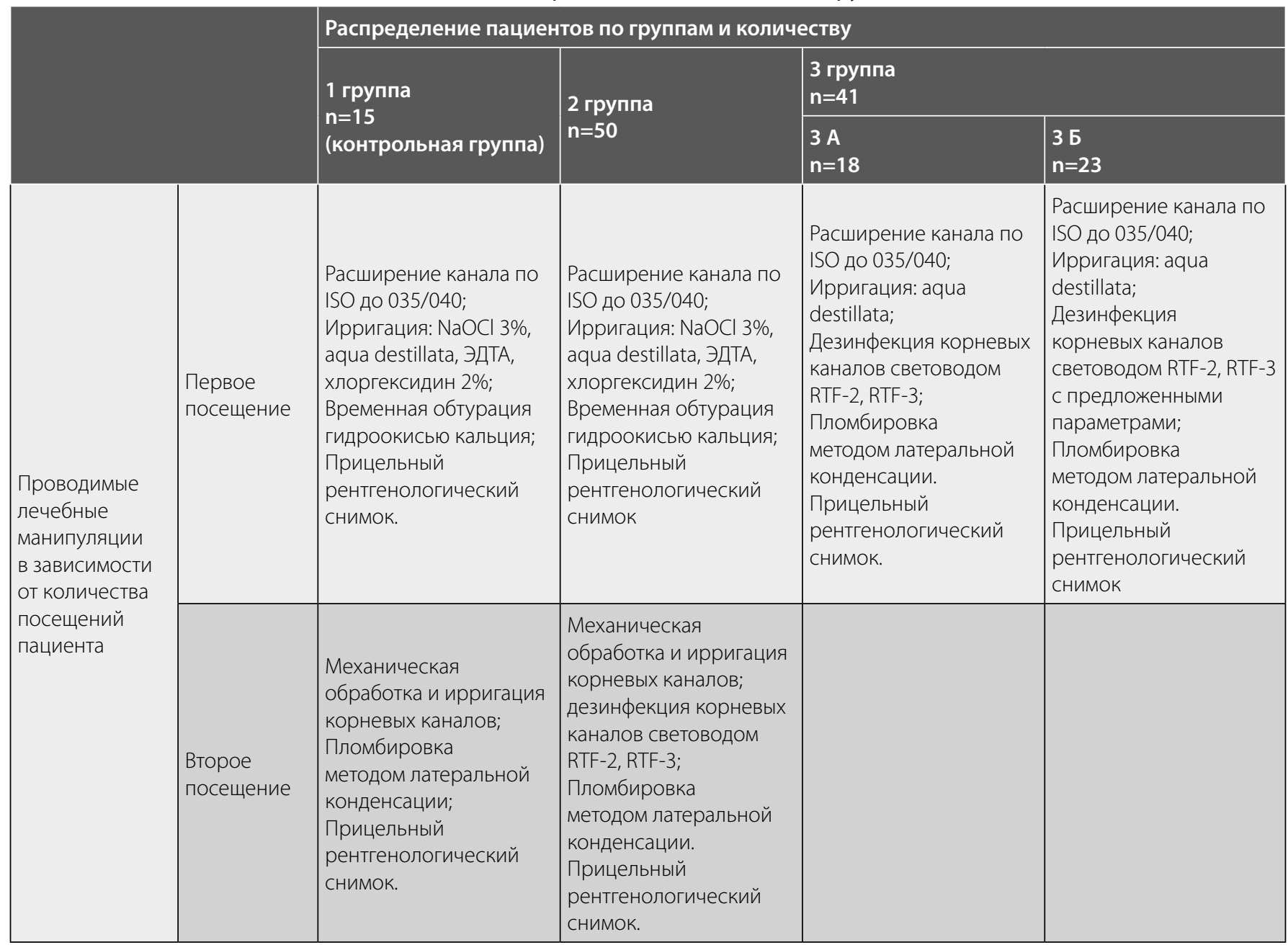

Таблица 2. Параметры лазерного излучения Er, Cr: YSGG лазера Waterlase iPlus с длинной волны 2780 нм используемые в работе

\begin{tabular}{|c|c|c|c|c|c|}
\hline & Насадка & Мощность & Частота импульсов & Воздух & Вода \\
\hline \multirow{2}{*}{$\begin{array}{l}\text { Дезинфекция } \\
2 \text { группа } \\
\text { ЗА группа }\end{array}$} & RTF2 & 1,25 Вт & 20 Гц & $10 \%$ & off \\
\hline & RTF3 & 1,25 Вт & 20 Гц & $10 \%$ & off \\
\hline \multirow{2}{*}{$\begin{array}{l}\text { Дезинфекция } \\
\text { З Б группа }\end{array}$} & RTF2 & 1,5 Вт & $40 Г ц$ & $35 \%$ & $25 \%$ \\
\hline & RTF3 & 1,5 Вт & 40 Гц & $35 \%$ & $25 \%$ \\
\hline
\end{tabular}

стрировал способность лазерного излучения проникать на глубину 1000 мкм и выше и оказывая при этом бактерицидный эффект.

Основной задачей лечения осложнённых форм кариеса является санация канально-корневой системы, заключающаяся в уничтожении максимального количества микроорганизмов и исключение повторного инфицирования. Результат лечения корневых каналов зависит от качественного и количественного состава ми- крофлоры корневых каналов или полного уничтожения микроорганизмов в системе корневых каналов [6].

\section{Цель работы}

Повышение эффективности лечения осложнённых форм кариеса путём использования бактерицидных и фунгицидных свойств Er, Cr: YSGG лазера с длиной волны 2780 нм при биомеханической обработке корневых каналов. 
Таблица 3. Результаты бактериологического исследования содержимого корневых каналов после механической и медикаментозной обработки $(\mathrm{n}=106)$

\begin{tabular}{|c|c|c|c|c|c|c|}
\hline \multirow{3}{*}{ Микрофлора } & \multicolumn{2}{|c|}{$\begin{array}{l}\text { Частота встречаемости,\% } \\
\text { (после обработки корневых } \\
\text { каналов) }\end{array}$} & \multicolumn{4}{|c|}{$\begin{array}{l}\text { Частота встречаемости,\% } \\
\text { (после обработки корневых каналов) }\end{array}$} \\
\hline & \multirow{2}{*}{$\begin{array}{l}\text { гнойный } \\
\text { пульпит } \\
\text { К04.02 } \\
\text { n=57 } \\
\text { абс./\% }\end{array}$} & \multirow{2}{*}{$\begin{array}{l}\text { некроз пульпы } \\
\text { К04.1 } \\
\text { n=49 } \\
\text { абс./\% }\end{array}$} & \multirow{2}{*}{$\begin{array}{l}\text { 1-я группа } \\
\text { n=15 } \\
\text { a6c. } / \%\end{array}$} & \multirow{2}{*}{$\begin{array}{l}\text { 2-я группа } \\
\mathrm{n}=\mathbf{5 0} \\
\text { абс. } / \%\end{array}$} & \multicolumn{2}{|l|}{$\begin{array}{l}\text { 3-группа } \\
\text { n=41 } \\
\text { aбc./\% }\end{array}$} \\
\hline & & & & & $\begin{array}{l}3 A \\
n=18\end{array}$ & $\begin{array}{l}35 \\
n=23\end{array}$ \\
\hline Streptococcus mitis & $1,75 \%$ & \begin{tabular}{|l|l|} 
& \\
$2,04 \%$ \\
\end{tabular} & \begin{tabular}{|l}
2 \\
$13,33 \%$ \\
\end{tabular} & - & - & - \\
\hline $\begin{array}{l}\text { Streptococcus } \\
\text { intermedius }\end{array}$ & - & $\begin{array}{l}1 \\
2,04 \% \\
\end{array}$ & $\begin{array}{l}1 \\
6,66 \% \\
\end{array}$ & - & - & - \\
\hline Candida albicans & $\begin{array}{ll}1,75 \% \\
\end{array}$ & \begin{tabular}{|l|l|}
2 \\
$4,1 \%$ \\
\end{tabular} & \begin{tabular}{|l|}
2 \\
$13,33 \%$ \\
\end{tabular} & - & - & - \\
\hline Candida krusei & - & \begin{tabular}{|l|}
1 \\
$2,04 \%$ \\
\end{tabular} & $\begin{array}{l}1 \\
6,66 \% \\
\end{array}$ & - & \begin{tabular}{|l|l|}
1 \\
$2,44 \%$ \\
\end{tabular} & - \\
\hline Enterococcus spp. & \begin{tabular}{|l|l|}
$1,75 \%$ \\
\end{tabular} & \begin{tabular}{|l|}
1 \\
$2,04 \%$ \\
\end{tabular} & \begin{tabular}{|l|}
2 \\
$13,33 \%$ \\
\end{tabular} & - & - & - \\
\hline Corinebacterium & $1,75 \%$ & - & $\begin{array}{l}1 \\
6,66 \%\end{array}$ & - & - & - \\
\hline
\end{tabular}

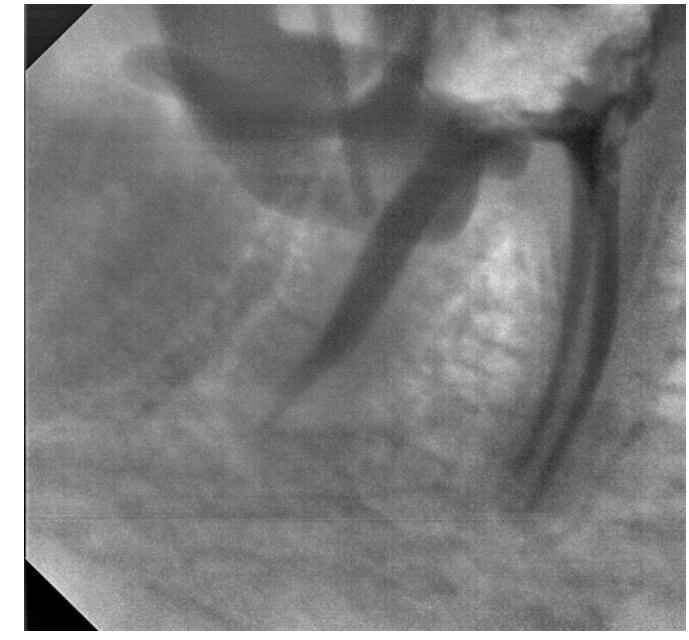

А - после лечения

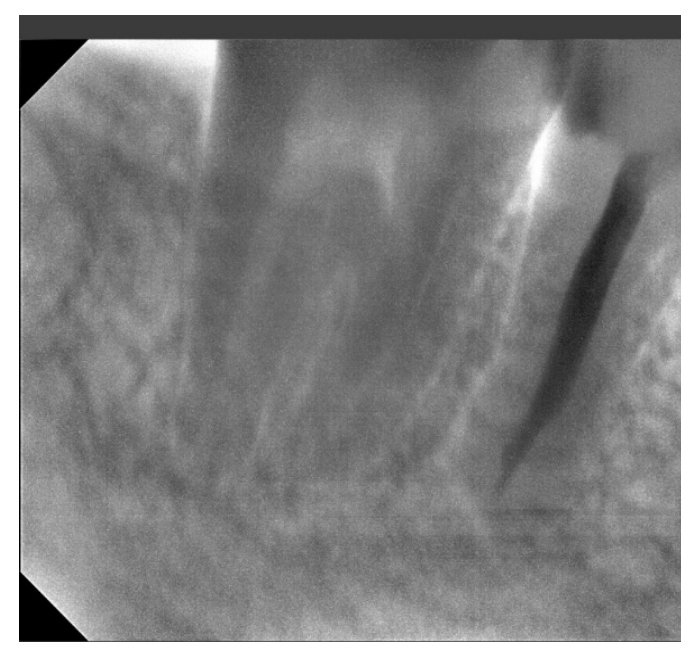

Б - через 1 год после лечения

Рис. 1. Прицельная рентгенография 4.6 зуба пациента И. с диагнозом гнойный пульпит

\section{Материалы и методы исследования}

Среди пациентов был проведён анализ клинических проявлений и диагностическое исследование с целью постановки диагноза гнойный пульпит (К04.02) и некроз пульпы (К04.1) и определения показаний к различным видам лечения с последующей оценкой их эффективности. Для постановки диагноза проводились традиционные методы обследования: сбор анамнеза, прицельное зондирование, визуальная оценка пульпы и содержимого корневых каналов (распад пульпы, гипертрофия тканей пульпы). Также использовались дополнительные методы исследования зубов - рентгенологическое, электроодонтодиагностика, бактериоскопическое изучение пульпы и содержимого корневых каналов. Пациенты были разделены на 3 клинические группы в зависимости от протокола лечения (таблица 1).

В поисках новых методов стерилизации корневых каналов, учитывая данные литературных источников нами был изучен и описан эффект воздействия итрий-скандий-галиево-гранатный (YSGG) твёрдотельного гидрокинетического лазера Waterlase iPlus с длинной волны 2780 нм (Er, Cr: YSGG) на микрофлору корневых кана- 
лов при лечении гнойного пульпита (К04.02) и некроза пульпы (К04.1), с последующим микробиологическим контролем. Для дезинфекции корневых каналов применяли волоконно-оптические насадки с радиальным излучением RTF-2 и RTF-3 диаметром 200 мкм и 300 мкм, соответственно (таблица 2). Конец насадки размещают на расстоянии 2 мм от апекса или вне контакта со стенкой изогнутого корневого канала.

\section{Результаты исслелования}

Результаты бактериологического исследования после механической и медикаментозной обработки корневых каналов показывают устойчивость Streptococcus viridans, Streptococcus mutans, Streptococcus mitis, Staphylococcus aureus, Enterococcus spp., Candida spp., Corinebacterium к традиционным методам механической и медикаментозной обработки корневых каналов, применяемых в первой группе. Во второй группе $\mathrm{Er}, \mathrm{Cr}$ : YSGG лазер с длинной волны 2780 нм в комплексеной биомеханической обработке позволяет добиться антибактериальной деконтаминации системы корневых (таблица 3). В третьей группе метод обработки канала $\mathrm{Er}, \mathrm{Cr}$ : YSGG лазером с длинной волны 2780 нм и дистиллированной водой оказался не эффективным в отношении Candida krusei в одном клиническом случае.
При анализе результатов проведённого лечения через 6 месяце, 1-1,5 года проводились основные и дополнительные методы исследования. Это было необходимо так как пациенты не предъявляли никаких жалоб на раннее вылеченный зуб. При объективном осмотре слизистая оболочка в области леченного зуба была бледно розового цвета без патологических изменений, перкуссия зуба безболезнена, пальпация в области по переходной складке также безболезнена, реставрация без сколов, герметизм корневых каналов не нарушен.

Через 6 месяце, 1-1,5 года по данным рентгенологического исследования отмечалось уменьшение очага деструкции костной ткани, или отсутствие воспалительных процессов в периодонте (рисунок 1).

Результаты наших исследований показывают, что применение гидрокинетического Er, Cr: YSGG лазера с длинной волны 2780 нм является надёжной альтернативой традиционным протоколам эндодонтического лечения, позволяя уменьшить количество применяемых ирригацинных растворов, внутриканальных паст, применение системных препаратов, а также инициировать более быструю реабилитацию пациентов после проведённого лечения.

\section{ЛИТЕРАТУРА}

1. Hannig C, Follo M., Hellwig E, A. Al-Ahmad. Visualization of adherent micro-organisms using different techniques // J. Med. Microbiol.—2010.—Vol. 59.—P. 1-7

2. Bussey K. A Comparison of Success With 1-Appointment and 2-Appointment Molar Root Canal Therapy // J. of Endod., № 12, vol. 30. — 2004. — P. 1126

3. Ricucci D, Bergenholtz G. Bacterial status in root-filled teeth exposed to the oral environment by loss of restoration and fracture or caries-a histobacteriological study of treated cases // Int End J.— vol. 36. — 2003.—P. 787-802

4. Calişkan M.K., Sen B. H. Endodontic treatment of teeth with apical periodontitis using calcium hydroxide: a long-term study.//Endod Dent Traumatol., 1996 0ct;12(5):215-21.doi:10.1111/j.1600-9657.1996.tb00518.x.PMID: 9206366

5. Moritz A., Beer F., Goharkhay K., Schoop U., StrassI M., Verheyen P., Walsh L. J., Wernisch J., Wintner E.: Oral Laser Application. ISBN-10: 1850971501, Berlin, 2006

6. Соломонов М.0 перелечивании. Акаадемический монолог / М. Соломонов. — М.: АМБ, 2014. — 209c. 